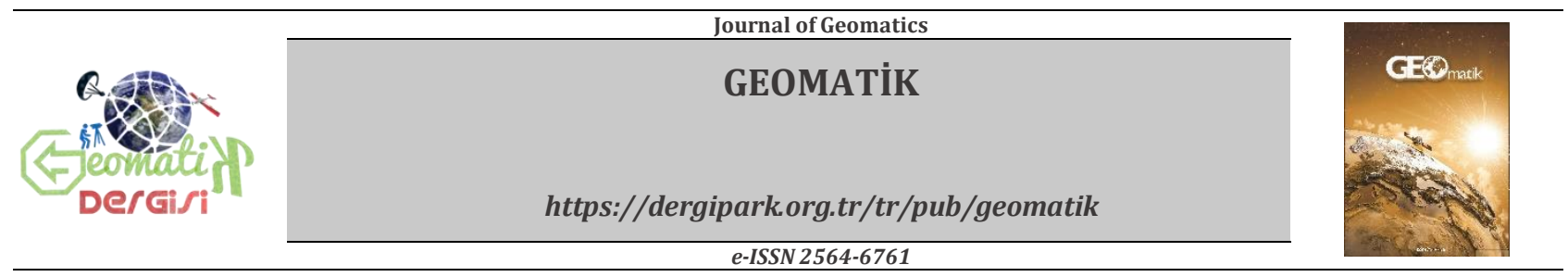

\title{
Zonguldak ve Ereğli Orman İşletme Müdürlükleri Orman Yangını Risk Alanlarının Belirlenmesi
}

\author{
Semra Dilekçi 1, Aycan Murat Marangoz ${ }^{* 2}$, Ayhan Ateşoğlu 3
}

1 Türkiye Elektrik İletim A.Ş., Ankara, Türkiye

2Zonguldak Bülent Ecevit Üniversitesi, Mühendislik Fakültesi, Geomatik Mühendisliği Bölümü, Zonguldak, Türkiye

${ }^{3}$ Bartın Üniversitesi, Orman Fakültesi, Orman Mühendisliği Bölümü, Bartın, Türkiye

\author{
Anahtar Kelimeler \\ Orman yangını \\ Uzaktan algilama \\ CBS \\ AHP \\ Orman yangını risk \\ haritası \\ SPSS
}

\begin{abstract}
ÖZ
Günümüzde doğal ve beșeri nedenlerle artan orman yangınlarının Uzaktan Algılama ve Coğrafi Bilgi Sistemleri teknikleriyle belirlenmesi, yapılacak müdahale ve planlama için oldukça önemli hale gelmiştir. Orman yangını risk alanlarını haritalamak yangına müdahale anlamında işgücü, zaman ve maliyet bakımından oldukça yararlı olacaktır. Orman yangını risk haritaları yangın oluşumuna ve davranıșına etki eden unsurları kısmen ortaya koymaktadır. Ülkemiz koşullarında, orman yangını risk haritaları yardımıyla özellikle arazi sınıflarındaki insan faktörüne ilișkin kullanımların yangın riskini değerlendirmelerdeki önemi net olarak anlaşılmaktadır. Bu çalışmada test alanı olarak Zonguldak ve Ereğli Orman İșletme Müdürlükleri seçilmiștir. Bu ișletmelerde, 2008-2019 yılları arasında meydana gelen 126 adet orman yangınının, yangın sicil formu incelenmiştir. Yangın çıkan alanlarda yangına neden olan insan faktörü, topoğrafik faktörler ve arazi kullanım sınıfları belirlenmiștir. Yerleşim ve yol ağlarına ilișkin vektörel çıkarımlar Google Earth üzerinden yapılmıştır. Topoğrafik veriler için Sayısal Yükseklik Modeli verisi kullanılmıștır. Arazi kullanım verileri için Landsat 8 uydu verisi üzerinden sınıflandırma işlemleri gerçekleştirilmiş, yangına konu olan sınıflar belirlenmiştir. Değerlendirmeye alınan her bir faktör için Analitik Hiyerarşi Süreci yöntemiyle uygunluk puanları belirlenmiștir. Bu sonuçlara göre Coğrafi Bilgi Sistemleri ortamında orman yangını risk haritası oluşturulmuştur. Bu harita; düşük, orta ve yüksek risk grubu olmak üzere sinıflandırılmıştır. Toplam alanın \%18'inin düşük, \%43'ünün orta, \%39'unun yüksek risk sınıfında olduğu görülmüștür. Sınıflandırılan haritanın doğruluk kontrolü için diskriminant analizi yapılmıştır. Analize göre çalıșmada elde edilen yangın tehlike indeksi değerlerinin, çalıșma alanını yangın risk gruplarına ayırmadaki önemi \%86 olarak çıkmıștır. Orman yangınlarına müdahalede ilgili bölge için önemli bir altlık oluşturacak bu araştırma, yangına hassas diğer bölgeler için de geliştirilebilecektir.
\end{abstract}

\section{Detection of Forest Fire Risk Areas of Zonguldak and Ereğli Regional Forest Directorate}

\author{
Keywords \\ Forest fire \\ Remote sensing \\ GIS \\ AHP \\ forest fire risk map \\ SPSS
}

\begin{abstract}
Nowadays, detecting the recent increase in naturally caused or human induced forest fires by using the techniques of Remote Sensing and Geographic Information Systems has become quite crucial for fire management and planning. Mapping the risk areas of fore st fires for fighting will be very beneficial in terms of labour, time and cost. In relation with the fighting forest fire, the forest fire risk maps partially reveal the factors that affect the fire outbreak and its course. Under the conditions of our country, the crucial use and help of these maps, particularly the ones related with the human factors in the land categories for evaluating the forest fire risk, have been clearly comprehended. In this study, a total of 126 forest fires that occur within the Zonguldak and Ereğli regional forest directorate between 2008 to 2019 were investigated using forest fire information form. Human factors, topographic factors and land use categories that caused fire in outbreak area
\end{abstract}




\begin{abstract}
were identified. The vector illustrations related to the settlements and road networks were made on Google Earth. For the topographic data, Digital Elevation Model input was used. The classification processes were carried out through Landsat 8 satellite data for the land usage data and the classes that had been subjected to the fires were identified, respectively. The congruity scores evaluated for corresponding factors were determined by Analytical Hierarchy Process method. The forest fire risk map was produced in Geographic Information Systems according to these results. Additionally, the low, medium and high risk groups were classified on it. It has been seen that $18 \%$ of the area was in low, $43 \%$ was in medium and $\% 39$ of it was in high forest fire risk group. For the accuracy validation of classified map, the discriminant analysis was performed. It has been observed that the importance of classifying fire risk groups of study area was $86 \%$ in relation with the assessment of fire risk index values obtained by the analysis that was conducted in this study. Being a significant base for interception of forest fires and fire management, this research might also be improved for other fire sensitive regions.
\end{abstract}

\section{GíRiş}

Afetler oluş zamanı belli olmayan durumlar olduğu için afetlere karşı sürekli hazır olmak gerekmektedir. Afet anında ve sonrasındaki hızlı müdahaleler insan hayatını kurtarmak ve oluşabilecek felaketlerin önüne geçebilmek adına oldukça önemlidir. Olayın gerçekleștiği andan itibaren her türlü yardıma hazır olunmalıdır ve bu da ancak iyi bir planlama ile mümkündür.

Ormanlar en önemli doğal kaynaklarımızdan biridir. Ancak ormanlar; nüfusun artması, kentleşme, sanayileşme, tarım arazilerinin genişlemesi gibi nedenlerden dolayı yoğun bir baskı altındadır. Bu baskının nedenlerinden biri de orman yangınlarıdır. Orman yangınları birçok ülkede olduğu gibi ülkemizde de çok büyük can ve mal kaybına yol açan doğal afetlerin başında gelmektedir (Çepel, 1995). Orman yangınlarının oluşumu ve yangın yayılma oranı, yanıcı madde tüketimi, yangın şiddeti gibi yangın davranış özelliklerini önceden tahmin etmek, yangınla mücadele açısından önemli bir adımdır (Yavuz ve Sağlam 2011; Yavuz vd. 2018).

Ülkemizin Akdeniz iklimi etkisi altında bulunan coğrafi konumu nedeniyle orman yangınları tamamen önlenemeyebilir (Doğanay ve Doğanay 2004). Türkiye'de orman yangınlarının genellikle Ege ve Akdeniz bölgesi kıyı bandı kesimindeki ibreli ormanlık alanlarda yoğunlaştığı görülmektedir (OGM, 2012). Genel olarak Akdeniz kıyı bandı Türkiye'deki orman yangınları için en büyük risk grubunu olușturmaktadırlar (Cömert vd 2019). Bu bölgeler için yangın risk alanları oldukça yüksek gruplarda yer almaktadır. Fakat son yıllardaki küresel ısınma ve sonrasında yaşanan ani iklim değişiklikleri, Dünya'da olduğu gibi ülkemizde de orman yangını risk alanların güncellenmesini gündeme getirmiştir (URL 1). Küresel ısınmaya bağlı olarak iklim ve arazi kullanımının değişmesi orman yangını tehditlerini arttırmaktadır (Öztürk vd 2010).

Küresel ısınma nedeniyle orman yangınlarına birinci derece riskli alanların yanında diğer alanlarının risk dereceleri her geçen gün hızla yer değiştirmektedir. $\mathrm{Bu}$ nedenle günümüzde orman yangını risk alanlarının, yangını etkileyen ana faktörlere göre tüm bölgeler için belirlenmesi, gelecekteki planlamalar için önem arz etmektedir. $\mathrm{Bu}$ amaçla, orman yangınlarının tespiti ve gözetlenmesi; doğru, erken, hızlı bir şekilde yapılması gerekmektedir. Bu bağlamda, uydu bazlı uzaktan algılama teknolojileri önemli bir araç olarak düşünülmektedir. Benzer olarak orman yangınlarıyla mücadelede başarı sağlanabilmesi için gerekli tedbirlerin alınması, gelişen teknolojinin etkin ve ekonomik bir şekilde kullanılması gerekmektedir (Erten vd. 2005; Dong vd. 2005; Malik vd. 2013; Matin vd. 2017; Karakuş vd. 2017). Yangın amenajmanında kullanılan önemli teknolojilerden bir diğeri Coğrafi Bilgi Sistemleri (CBS)'dir (Pradhan vd. 2007; Bingöl, 2017). CBS sayesinde istenilen bilgilere ulaşmak daha hızlı, kolay ve ekonomik olmaktadır. Böylece, sadece yangın sırasında değil, yangın öncesi ve sonrasında yapılacak çalışmalar için de oldukça yararlı veriler elde edilebilmektedir (Küçük ve Bilgili 2006; Adıgüzel vd. 2016; Ahmad ve Goparaju, 2019).

Bu çalışmanın amacı, Batı Karadeniz bölgesinde yer alan Zonguldak ve Ereğli Orman İşletme Müdürlükleri (OIM) sınırları içerisinde küresel ısınma neticesinde gelecekte muhtemel orman yangını tehditlerine yönelik, risk alanlarının tespit edilerek planlamalara altllk olarak kullanılacak orman yangını risk haritasının oluşturulmasıdır. Çalışma geçmiş yıllardaki orman yangınlarını esas alarak salt arazi faktörlerine göre gerçekleștirilmiştir. Uzun yllar iklim ve meteorolojik veriler ışığında orman yangınları risk alanlarının oluşturulmasına entegre edilerek katkı sunabilecek orman yangını risk harita verisi hazırlanmıştır. Çalışmada uydu görüntü verilerinden yararlanılarak AHP (Analytic Hierarchy Process/Analitik Hiyerarşi Süreci) tekniğine göre CBS ortamında yangın risk haritası oluşturulmuştur.

\section{1. Çalışma Alanı ve Özellikleri}

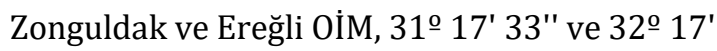

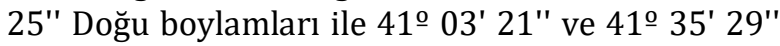
Kuzey paralelleri arasında kalan yaklaşı 215000 ha büyüklüğünde bir bölgedir (Șekil 1). 


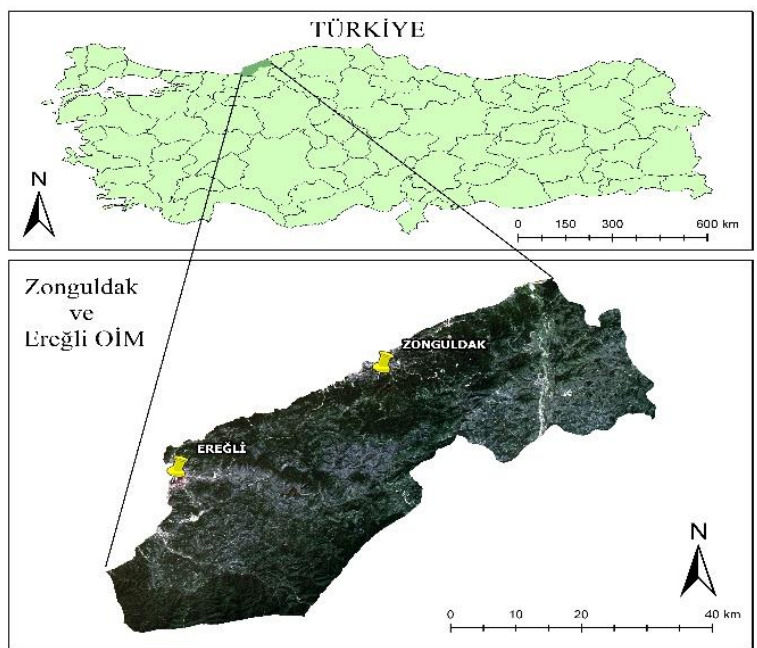

Şekil 1. Çalışma Alanı (URL 2)

Zonguldak, Perșembe, Göldağı, Yayla, Çaycuma, Kozlu şeflikleri; Zonguldak OİM'ye bağlıdır. Ereğli, Cuma, Alaplı, Çaylıŏlu, Suludere, Yalnızçam, Kocaman, Bendere şeflikleri ise Ereğli OİM'ye bağlıdır.

Zonguldak ili bol yağışlı bir iklime sahiptir ve yerüstü su kaynakları bakımından zengindir. İlde çok sayıda akarsu bulunmakla birlikte Filyos Çayı dışında büyük akarsu yoktur. Buradaki akarsular, Zonguldak ili alanını sık bir vadi ağı ile parçalamıștır. Yeryüzü şekilleri genel olarak dağlıktır. Dağlar; kuzey kesimlerde 1000 metreyi bulmaz iken orta kesimlerde 1200 metreyi aşmaktadır. Dağların, güneyde 2000 metreye kadar ulaştığı yerler mevcuttur. Dağlar kıyıya paralel üç sıra oluşturduğundan kıyı ve iç kesimler arasında ulaşım zordur.Kıyıya yakın yükseltilerin oluşturduğu dağ sırasının altında zengin taşkömürü madeni yatakları bulunmaktadır (URL 3).

Batı Karadeniz, bitki coğrafyası bakımından Avrupa-Sibirya flora alanının Öksin alt flora alanında bulunmaktadır (Ateşoğlu ve Melemez 2015). Zonguldak ili topraklarının \%56'sı ormanlık alan olup \%88'i koru \%12'si bataklı orman niteliğindedir. Kayın, meșe, gürgen, kestane, çınar, ıhlamur ve kızılağaç bașta olmak üzere $\% 70$ 'i geniş yapraklı; karaçam, sarıçam, kızılçam ve sahil çamı olmak üzere \%30'u iğne (ibreli) yapraklı ormanlar mevcuttur (URL 3).

Tarım ve Orman Bakanlı̆̆ı, Meteoroloji Genel Müdürlüğü tarafından hazırlanan 2018 yılı iklim değerlendirmesi raporuna göre Türkiye ylllk ortalama sıcaklık anomalisi özellikle 2000'li yıllardan bu yana artış göstermektedir (URL 4). Ayrica yıllık ortalama sicaklık siralamasina bakıldığında 1981-2010 yılı ortalama sıcaklık değerine göre her yll artış gösteren sıcaklık değerleri göze çarpmaktadır. Bu bağlamda çalışma alanı içerisinde orman ve fundalık alanlarının yanıcı madde olarak fazlaca yer alması, iğneli türlerin de bulunması ve ayrıca yukarıda belirtilen anomalilere uygun olarak Türkiye'de gelecekte potansiyel orman yangını sahalarının Batı Karadeniz bölgesini kapsayabileceği gerçeği göz önünde bulundurularak çalışma alanı seçimi gerçekleştirilmiştir. Ayrıca, Türkiye 2018 yılı ortalama sıcaklık farklarının coğrafi dağlımına bakıldığında da Zonguldak ve civarının $1.1-2{ }^{\circ} \mathrm{C}$ artması ve muhtemel bu sürecin devam edeceği varsayımı kuvvetlenmektedir (Şekil 2).
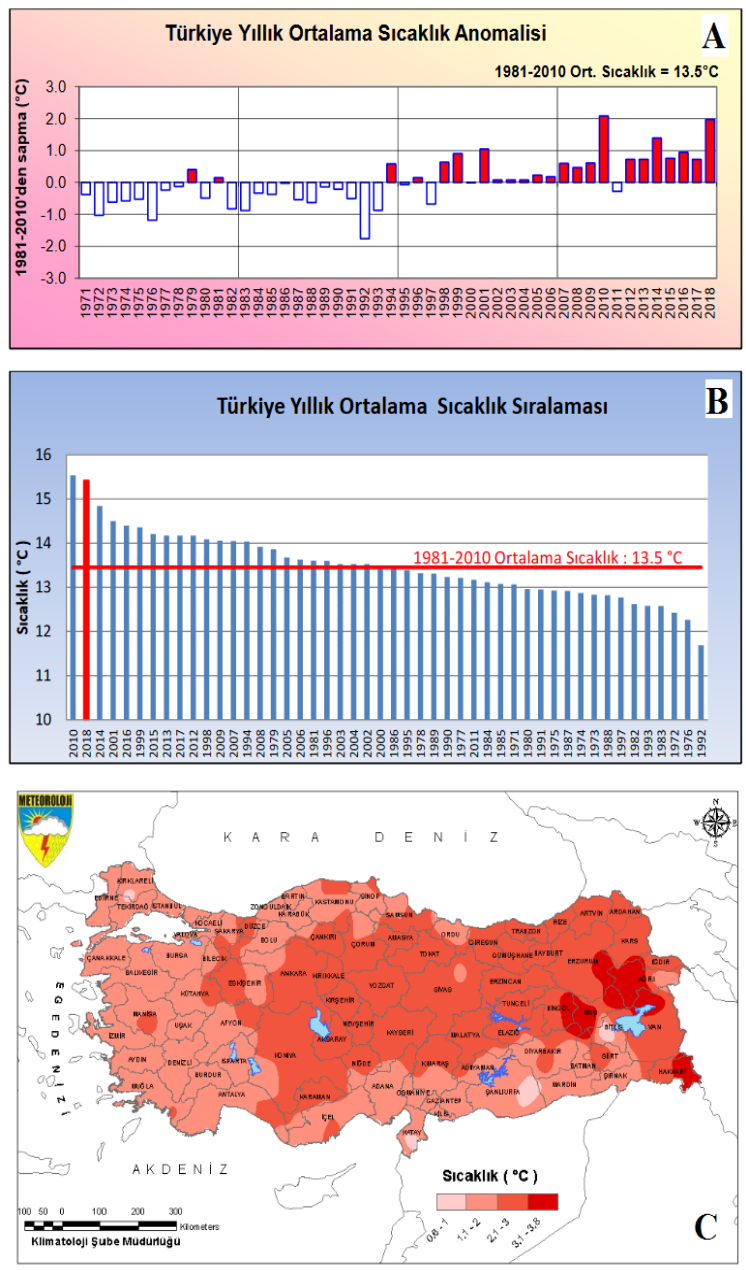

Şekil 2. Türkiye Yıllık Sıcaklık Anomalisi (A), Türkiye Yıllık Ortalama Sıcaklık Sıralaması (B), Türkiye 2018 Yılı Ortalama 1981-2010'a Göre Sıcaklık Farklarının Coğrafi Dağılımı (C) (URL 4).

\section{YÖNTEM}

Çalışma alanının belirlenmesinden çalışma alanının risk haritasının doğruluk kontrolüne kadar olan süreç Tablo 1'de verilmiştir.

Zonguldak ve Ereğli OİM'de yangına neden olan faktörlerin tespiti ve yangının daha çok nerelerde çıktığını belirlemek için çalışma alanına ait 20082019 yılları içerisindeki yangın sicil fişlerine, arşiv araştırması sonucunda ulaşılmıştır. Bunun için Zonguldak Orman Bölge Müdürlüğü (OBM), Zonguldak ve Ereğli OİM arşivlerindeki yangın sicil fişleri incelenerek toplam 126 adet orman yangını sicil fişine ulaşılmıştır. Bu yangınlardan 25 adedi yangın risk haritasında doğruluk değerlendirmesi yapmak üzere ayrılmıştır. 
Tablo 1. Çalışmanın İş-Akış Şeması

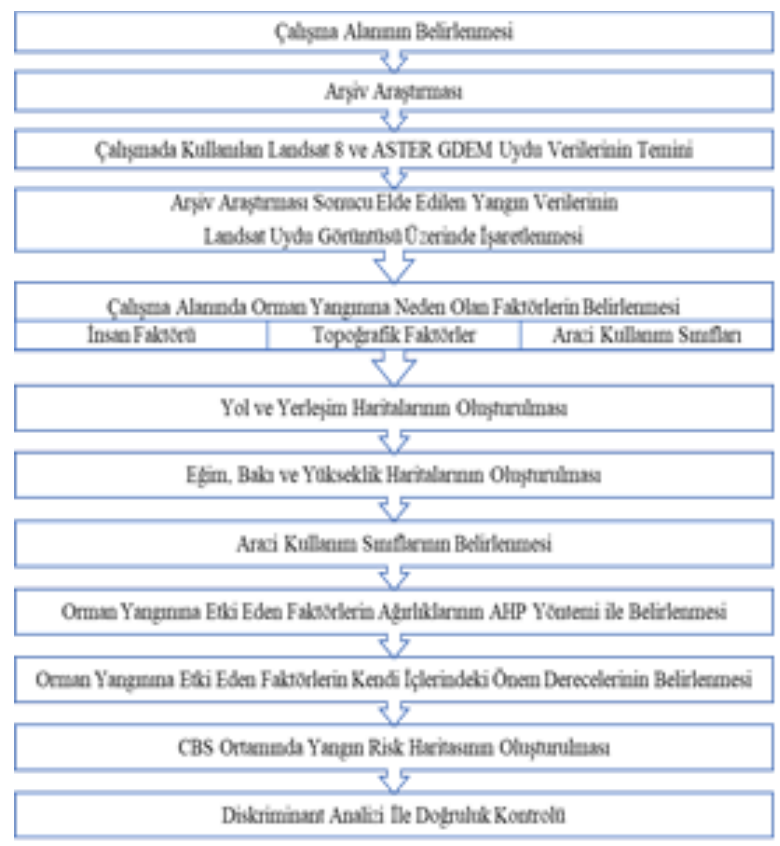

Ateşoğlu (2014), Batı Karadeniz sınırları dahilinde Bartın ili ve çevresi için yaptığı çalışmada orman yangınlarında etkili altı önemli faktör tespit etmiştir. Bu faktörler tespit edilirken yangın sicil fişleri, ilgili işletme şeflerinin görüşleri ve literatürdeki diğer çalışmalardan faydalanılmıștır. Benzer olarak Zonguldak ve Ereğli OİM için toplam 126 yangın sicil fişlerinin incelenmesi ile benzer sonuçlara ulaşılmıştır. 2008-2019 yılları içerisindeki yangın yerleri, yangın sicil fișlerindeki koordinatlar yardımıla 15.08.2015 tarihli Landsat 8 uydu görüntüsü

(Landsat_Scene_ID:LC81780312018227LGN00;Lan dsat_Product_ID:LC08_L1TP_178031_20180815_20 180828_01_T1; File Date: 2018-08-28) (URL 5) üzerinde işaretlenmiştir. Aynı uydu görüntü verisi arazi örtü/kullanım sinıflandırılması için de kullanılmıștır (Şekil 3). Sınıflandırma işleminde kontrollü sınıflandırma yöntemlerinden olan Maksimum Benzerlik Yöntemi seçilmiştir.

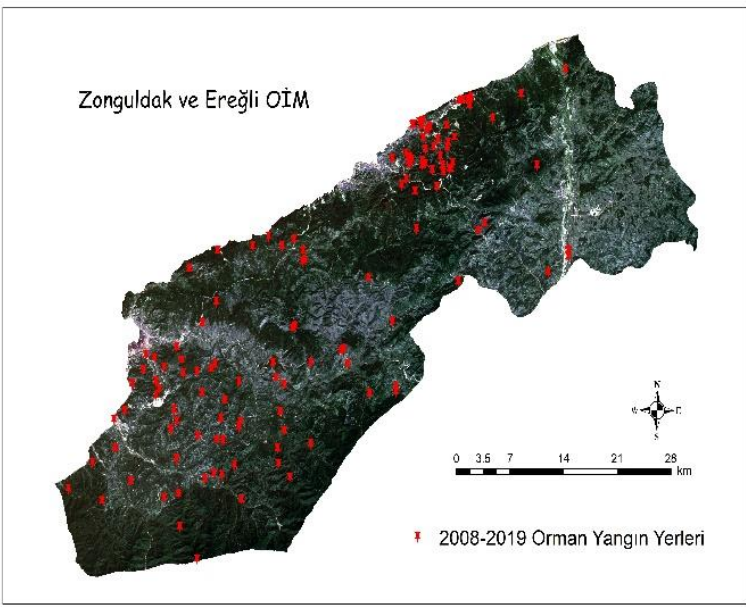

Şekil 3. 2008-2019 Yılları İçerisindeki Orman Yangınları
Bir bölgenin topografik durumu yangınları etkileyen önemli faktörlerdendir. Özellikle yangın davranıșı hakkında bilgi vermektedir. Ayrıca arazinin değişik tipleri, iklim ve günlük hava halleri koşullarında değişikliklere neden olur (Goldammer ve Nikolov; 2009; Mahdavi vd. 2012; Özşahin 2014; Gigovic vd. 2018).

$\mathrm{Bu}$ nedenle topografyanın yangınlarla olan ilişskisi arazinin çeşitli durumuna (eğim, bakl, yükseklik) göre incelenmelidir. Tüm topoğrafik şartların belirlenmesi amacıyla ASTER Global Dijital Yükseklik Modeli (GDEM) 30m verisi (URL 6) kullanılmıştır.

Yangın formları incelenerek yangın başlama noktaları ve bölme numaraları ilişkilendirildiğinde, yangının nasıl ve nerede oluşabileceğine ilișkin fikirler elde edilebilmektedir. Çalışma alanında genel olarak yangın başlama noktasına göre yangın görülen yerlerin \% 90'dan fazlası yol kenarı, tarla kenarı ve yerleşim yeri kenarlarında olduğu gözlenmiştir. Uydu görüntü verisinin arazi kullanım sınıflarının oluşturulmasında yangının en çok görüldüğü doğal bitki örtüsü ile birlikte bulunan tarım alanları ve çevresi başta olmak üzere orman alanları ve diğer sınıflar (yerleşim, yol, kayalık vb.) arazi sınıfları olușturulmuștur. Çünkü insan ve araçların hareketliliğinde rol oynayan yollar, insan kaynaklı orman yangınlarının meydana gelişinde önemli rol oynarlar. Çalışma alanı içerisinde birçok kırsal yerleşim alanları da mevcuttur.

Bölgedeki yangınların genelde insan kaynaklı olması nedeniyle insan hareketliliğine neden olan yerleşim ve yol verilerinin vektörleştirilmesinden sonra, CBS ortamında buffer analizi ile yangın sicil fiși verilerinin dağllımına ve yoğunluklarına uygun olacak şekilde yerleşim ve yol koridorları oluşturulmuştur. Çalışmada kullanılan verilerin alana göre kesilmesi, sınıflandırma, eğim, bakı, yükseklik haritalarının oluşturulması, sınıflandırma işleminin doğruluk analizi, yerleșim ve yol koridorlarının oluşturulması, ArcGIS 10.5 programı kullanılarak gerçekleştirilmiştir. Elde edilen tüm faktörlerin haritaları CBS ortamında hazırlanmış ve $30 \mathrm{~m} \times 30 \mathrm{~m}$ piksel boyutlu raster veri formatına çevrilerek analize hazır hale getirilmiştir.

Tüm faktörlerin belirlenmesinden sonra, çalışma alanında yangın risk alanlarının belirlenmesi amacıyla her bir faktöre ilişkin ağırlık katsayıları AHP yöntemiyle hesaplanmiştır. Kriterlerin belirlenmesinden sonra değerlendirmeye alınan her bir kriter için uygunluk puanları saptanmıştır. Puanların saptanmasında yine AHP kullanılmıştır. AHP yöntemi, 1977 yılında Thomas L. Saaty tarafından geliştirilen çok ölçütlü karar verme tekniklerinden biridir. Karar alırken grup ya da bireyin önceliklerini de dikkate alan, nitel ve nicel değişkenleri bir arada değerlendirebilen matematiksel bir yöntemdir. Hiyerarşik yapının oluşturulması, ikili karşılaştırmaların yapılması ve sentez aşamalarından oluşmaktadır (Kadak, 2006).

AHP, karar verme sürecinde kararı oluşturan faktörlerin bir bütün içerisinde ve birbirleriyle 
ilişkili olarak değerlendirilmesini kapsayan bir yöntemdir. Faktörlerin değerlendirilmesinin yanında bunların karar noktaları üzerinde de etkileri bu yöntem sayesinde ortaya konulabilmektedir. Bu süreçte kararı etkileyen faktörlerin önem dereceleri karar vericiler tarafindan belirlenir ve bu kapsamda önceden tanımlanmış olan puanlama (1-9) yapılır. $\mathrm{Bu}$ yöntem sayesinde karar vericilerin vermiş oldukları puanlamaların tutarlılıkları kontrol edilir ve tekrar düzenlemeler yapılabilir. Çalışmada Ateşoğlu (2014)'in Batı Karadeniz'de yer alan çalışma alanından elde etmiş olduğu AHP önem derecelendirmeleri ve ağırlı değerleri kullanılmıștır. Her bir kriterin önem dereceleri, Bartın Orman Fakültesi Orman Mühendisliği öğretim üyeleri ve Zonguldak Orman Bölge Müdürlüğü, Bartın Orman İşletme Müdürlüğü ilgili teknik uzmanlara sorularak 1-9 arasında oluşturulmuş değerlerdir. Bu kapsamda her bir kriter için yangın sicil fişlerinin analiz ve değerlendirilmesi neticesinde ilgili sınıflandırma, koridor değerleri belirlenmiş ve uzman kişilerce birlikte puanlamalar yapılmiştır.

Analize dahil edilmeyen 25 orman yangınının, bu risk gruplarından hangisine düştüğüne bakılmıștır. Daha sonra SPSS programı kullanılarak diskriminant analizi yapılmıștır. Diğer bir adı ayırma analizi olan Diskriminant analizi, veri setinde bulunan verilerin değişken gruplarına atanırken taşıdığı özelliklere göre ayrım yapar. Diskriminant analizi bağımsız değişkenlerin bağımlı değişkenleri etkilemelerine göre ya aynı ya da farklı gruplara göre sınıflandırılmasını sağlar. $\mathrm{Bu}$ analizin başlıca amaçları; verilerin sınıflanıp sınıflanamayacağını test etmek, değișkenleri sinıflamak, gruplar arasındaki farklılıkları incelenmek, bağımlı değişkende bağımsız değişkenlerce açıklanan varyansı göstermek, bağımlı değişkene göre yapılan sınıflandırmada bağımsız değișkenlerin öncelik sırasını irdelemek, grupları ayırırken önemi düşük olan değişkenleri elemektir.

Sonuç olarak, çalışma alanı için oluşturulan orman yangını risk haritası yardımıyla orman yangını risk alanları, en basit anlamda üç sınıfta düşük, orta ve yüksek olarak gruplandırılarak sınıflandırılmıştır.

\section{BULGULAR}

Arazi örtü tipini belirleyebilmek amacıyla 2018 yılı Ağustos ayına ait Landsat 8 uydu görüntüsü sınıflandırılmıştır. Temel amaç yanıcı madde miktarı ve bu maddelerin bulunduğu alanların çıkarılması olduğu için, orman ve orman alanı içeren alanların tespiti oldukça önemlidir. Bölgenin arazi kullanımı düşünüldüğünde salt ormanlık alan ve ormanlık alanları da kapsayan heterojen tarım alanları yanıcı madde barındıran iki ana sınıf olarak belirlenmiștir. Bölgedeki su varlığı ve diğer alanlar ise sınıflandırmanın diğer iki sınıfını oluşturmak üzere dört ana arazi örtü/kullanım sınıfı oluşturulmuştur (Şekil 4). Diğer alanlar; yol, kırsal-kentsel yerleşim alanları, açık alanlar vb. sınıflardan oluşmaktadır.

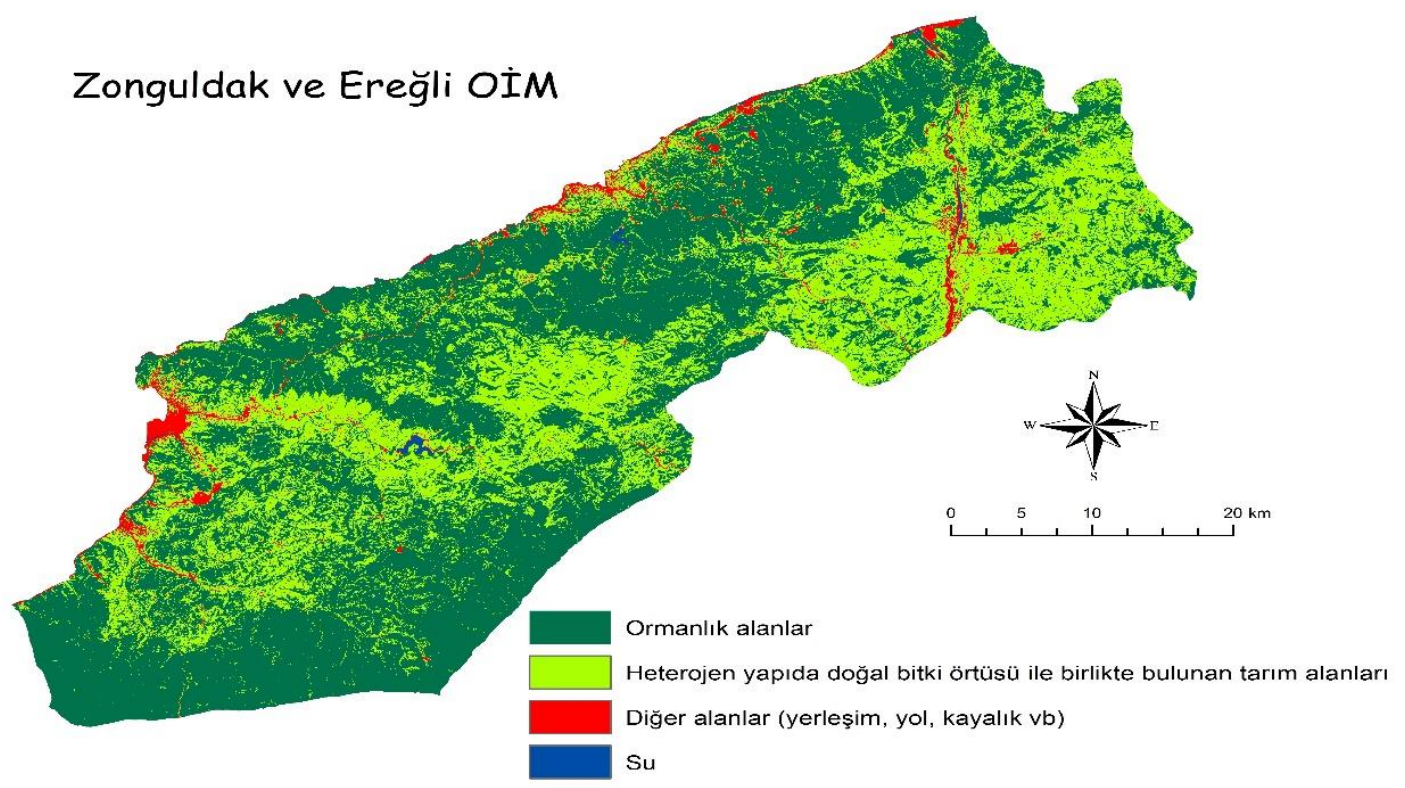

Şekil 4. Arazi Örtü/Kullanım Sınıfları Haritası

Landsat 8 uydu görüntü verisine, literatürde yoğun olarak kullanılan piksel tabanlı sınıflandırma algoritmalarından Maksimum Benzerlik Yöntemi uygulanmıştır. Gerçekleștirilen sınıflandırmanın genel doğruluğu \%94 olarak hesaplanmıştır. Sınıflandırma sonucunda birbirine karışan ve sınıflandırma doğruluğunu düșüren sınıflar diğer alanlar ve tarım alanlarıdır. Bu yüzden bu sinıflarda kullanıcı ve üretici doğruluğunun düşük olduğu görülmüștür (Tablo 2). 
Tablo 2. Sınıflandırma Doğruluk Değerlendirmesi ve Hata Matrisi

\begin{tabular}{|c|c|c|c|c|c|c|}
\hline & A1 & A2 & $\mathbf{A 3}$ & A4 & $\Sigma$ & $\begin{array}{c}\text { Kullanıcı } \\
\text { Doğruluğu } \\
(\%)\end{array}$ \\
\hline $\begin{array}{l}\text { Orman } \\
\text { alanları (A1) }\end{array}$ & 156 & 0 & 0 & 0 & 156 & 100 \\
\hline $\begin{array}{l}\text { Heterojen } \\
\text { yapıda doğal } \\
\text { bitki örtüsü } \\
\text { ile birlikte } \\
\text { bulunan tarım } \\
\text { alanları (A2) } \\
\end{array}$ & 2 & 122 & 29 & 0 & 153 & 80 \\
\hline $\begin{array}{l}\text { Diğer alanlar } \\
\text { (A3) }\end{array}$ & 0 & 1 & 183 & 0 & 184 & 99 \\
\hline $\begin{array}{l}\text { Sulak alanlar } \\
\text { (A4) }\end{array}$ & 0 & 0 & 0 & 32 & 32 & 100 \\
\hline$\Sigma$ & 158 & 123 & 212 & 32 & 525 & \\
\hline $\begin{array}{l}\text { Üretici } \\
\text { Doğruluğu (\%) }\end{array}$ & 99 & 99 & 86 & 100 & & \\
\hline
\end{tabular}

Arazi toppografik durumunun belirlenmesi amacıyla ASTER GDRM 30 m verisi yardımıyla eğim, bakı, yükseklik haritaları oluşturulmuștur (Șekil 5).

Köyler dahil olmak üzere yerleşim yerleri Google Earth üzerinden vektörleștirilmiștir. Yol verileri Zonguldak OBM'den alınan meșcere haritasından temin edilmiştir. Eksik kalan kısımlar ise Google Earth üzerinden vektörleștirilmiștir. Sonuç olarak CBS ortamında yerleşim ve yol koridorları oluşturulmuştur (Şekil 6).

Landsat 8 uydu görüntüsü verisi üzerinden elde edilen sınıflandırma haritaları ve ASTER GDEM $30 \mathrm{~m}$ uydu görüntüsü kullanılarak elde edilen eğim, bakı, yükseklik haritaları piksel boyutu $30 \mathrm{~m} \times 30 \mathrm{~m}$ raster veri olarak değerlendirmeye alınmışlardır.

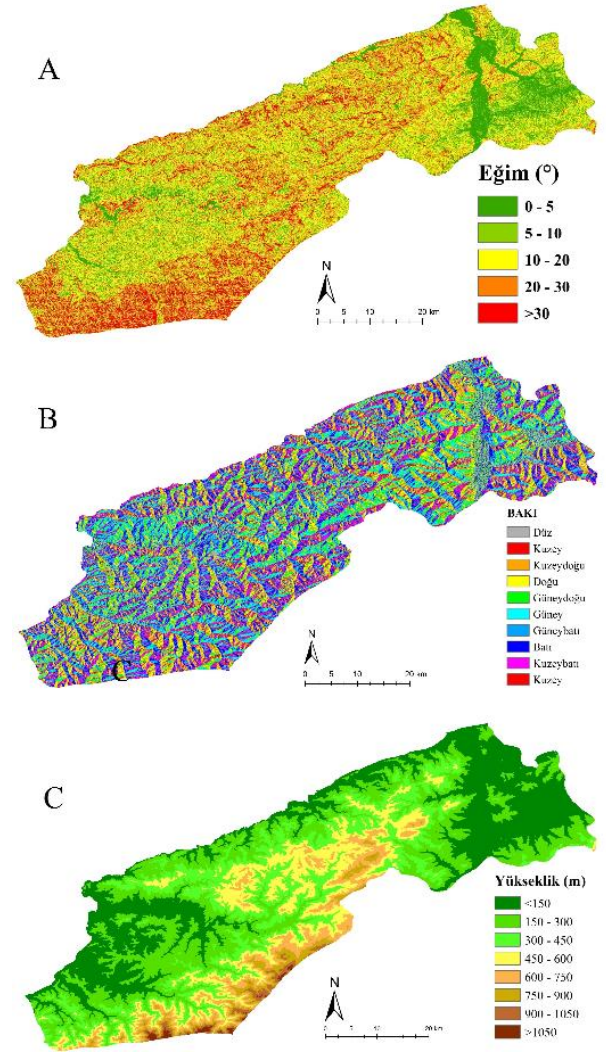

Şekil 5. Ĕgim (A), Bakı (B), Yükseklik (C) Haritaları

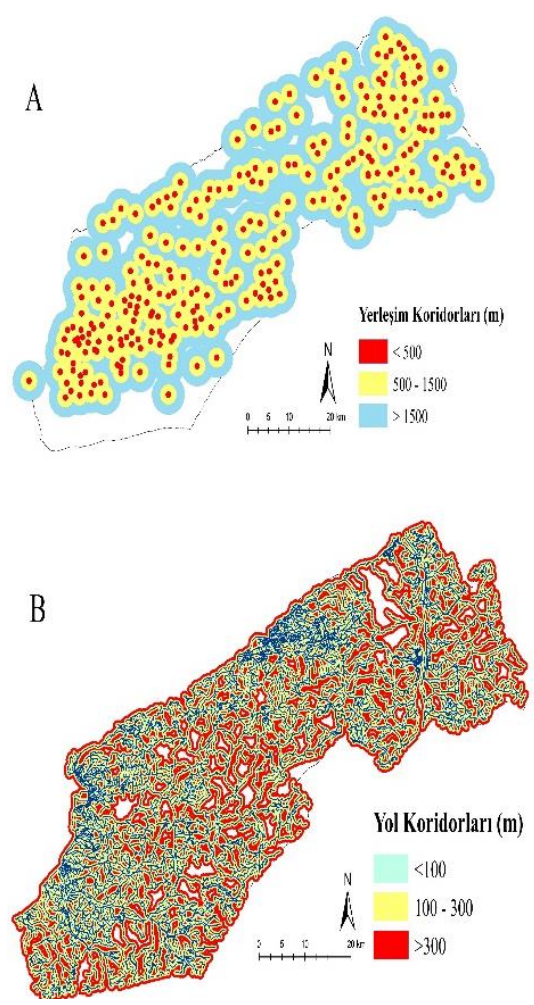

Şekil 6. Yerleşim Koridorları (A), Yol Koridorları (B)

Ateşoğlu (2014)'in daha önce Batı Karadeniz'de yer alan çalışma alanından elde etmiş olduğu veriler kullanılmış ve analiz için gerekli altlık haritaların hazırlanılmasından sonra belirlenen kriterler için uygunluk puanları belirlenmiştir. (Tablo 3). İlgili değişkenler için önem dereceleri Bartın Orman Fakültesi Orman Mühendisliği öğretim üyeleri ve Zonguldak Orman Bölge Müdürlüğü, Bartın Orman İşletme Müdürlügü ilgili teknik uzmanlara sorularak 1-9 arasında oluşturulmuş değerlerdir.

Tablo 3. Orman Yangın Risk Değişkenleri İçin Önem Derecelendirmeleri

\begin{tabular}{|l|l|l|l|}
\hline $\begin{array}{l}\text { Değişkenl } \\
\text { er }\end{array}$ & Sınıflar & $\begin{array}{l}\text { Önem } \\
\text { Derecesi }\end{array}$ & $\begin{array}{l}\text { Yangın } \\
\text { Tehlike } \\
\text { sınıfı }\end{array}$ \\
\hline & $\begin{array}{l}\text { Heterojen tarım } \\
\text { alanları/Doğal } \\
\text { bitki örtüsü ile } \\
\text { birlikte bulunan } \\
\text { tarım alanları }\end{array}$ & 9 & Yüksek \\
$\begin{array}{l}\text { Arazi } \\
\text { örtü/ } \\
\text { Kullanım } \\
\text { sinıfları }\end{array}$ & $\begin{array}{l}\text { Karıșık-geniş } \\
\text { yapraklı } \\
\text { ormanlar }\end{array}$ & 5 & Orta \\
\hline $\begin{array}{l}\text { Diğer alanlar } \\
\text { tarım, yerleşim, } \\
\text { açık alanlar vd.) }\end{array}$ & 3 & Düşük \\
\hline
\end{tabular}




\begin{tabular}{|c|c|c|c|}
\hline Eğim $\left(^{\circ}\right)$ & $\begin{array}{l}0-5 \text { (Düz) } \\
5-10 \quad \text { (Orta } \\
\text { eğimli) } \\
10-20 \quad \text { (Çok } \\
\text { eğimli) } \\
20-30 \text { (çok dik) } \\
>30 \text { (Çok dik ve } \\
\text { Sarp) }\end{array}$ & $\begin{array}{l}2 \\
5\end{array}$ & $\begin{array}{l}\text { Düşük } \\
\text { Orta } \\
\text { Yüksek } \\
\text { Orta } \\
\text { Düsük }\end{array}$ \\
\hline Bakl & $\begin{array}{l}\text { Kuzey } \\
\text { Kuzeydoğu } \\
\text { Kuzeybatı } \\
\text { Güney } \\
\text { Güneydoğu } \\
\text { Güneybatı } \\
\text { Batı } \\
\text { Doğu }\end{array}$ & $\begin{array}{l}5 \\
2 \\
2 \\
9 \\
5 \\
5 \\
7 \\
5\end{array}$ & $\begin{array}{l}\text { Orta } \\
\text { Düşük } \\
\text { Düşük } \\
\text { Yüksek } \\
\text { Orta } \\
\text { Orta } \\
\text { Yüksek } \\
\text { Orta }\end{array}$ \\
\hline $\begin{array}{l}\text { Yükseklik } \\
\text { (m) }\end{array}$ & $\begin{array}{l}<200 \\
200-400 \\
>400\end{array}$ & $\begin{array}{l}5 \\
3 \\
1\end{array}$ & $\begin{array}{l}\text { Yüksek } \\
\text { Orta } \\
\text { Düşük }\end{array}$ \\
\hline $\begin{array}{l}\text { Yerleşim } \\
\text { e olan } \\
\text { uzaklık } \\
(\mathrm{m})\end{array}$ & $\begin{array}{l}<500 \\
500-1500 \\
>1500\end{array}$ & $\begin{array}{l}2 \\
7 \\
3\end{array}$ & $\begin{array}{l}\text { Düşük } \\
\text { Yüksek } \\
\text { Orta }\end{array}$ \\
\hline $\begin{array}{l}\text { Yola olan } \\
\text { uzaklık } \\
\text { (m) }\end{array}$ & $\begin{array}{l}<300 \\
300-600 \\
>600\end{array}$ & $\begin{array}{l}7 \\
5 \\
2\end{array}$ & $\begin{array}{l}\text { Yüksek } \\
\text { Orta } \\
\text { Düșük }\end{array}$ \\
\hline
\end{tabular}

Her bir kriterin etki durumu göz önünde bulundurularak ikili karşılaştırma matrisleri oluşturulmuştur ve her bir kritere ilişkin ağırlık değerleri hesaplanmıştır. Zonguldak ve Ereğli OİM için hesaplanan ağırlık puanlarına göre ağırlık değeri en fazla olan \%41 değeri ile arazi örtü tipi olmuştur. Bunu \%18 ağrlık değeri ile eğim ve yola mesafe takip etmektedir (Tablo 4).

Tablo 4. Orman Yangınına Etki Eden Kriterlerin İkili Karşılaştırmaları, Ağırlık Değerleri ve Tutarlılık Oranı

\begin{tabular}{|c|c|c|c|c|c|c|c|}
\hline $\begin{array}{c}\text { Değiş } \\
\text { ken }\end{array}$ & $\mathbf{C 1}$ & $\mathbf{C 2}$ & $\mathbf{C 3}$ & $\mathbf{C 4}$ & $\mathbf{C 5}$ & $\mathbf{C 6}$ & Ăğırlk \\
\hline $\mathrm{C} 1$ & 1 & 3 & 5 & 4 & 5 & 3 & 0.41 \\
\hline $\mathrm{C} 2$ & $\begin{array}{c}1 / \\
3\end{array}$ & 1 & 3 & 2 & 3 & 1 & 0.18 \\
\hline $\mathrm{C} 3$ & $\begin{array}{c}1 / \\
5\end{array}$ & $\begin{array}{c}1 / \\
3\end{array}$ & 1 & $\begin{array}{c}1 / \\
2\end{array}$ & 1 & $1 / 3$ & 0.06 \\
\hline $\mathrm{C} 4$ & $\begin{array}{c}1 / \\
4\end{array}$ & $\begin{array}{c}1 / \\
2\end{array}$ & 2 & 1 & 2 & $1 / 2$ & 0.11 \\
\hline $\mathrm{C} 5$ & $\begin{array}{c}1 / \\
5\end{array}$ & $\begin{array}{c}1 / \\
3\end{array}$ & 1 & $\begin{array}{c}1 / \\
2\end{array}$ & 1 & $1 / 3$ & 0.06 \\
\hline $\mathrm{C} 6$ & $\begin{array}{c}1 / \\
3\end{array}$ & 1 & 3 & 2 & 3 & 1 & 0.18 \\
\hline
\end{tabular}

*Tutarlılık oranı: 0.011

C1: Arazi örtü tipi; C2: Eğim; C3: Bakı; C4: Yükseklik; C5:

Yerleşim durumu; C6: Yol durumu
Sonuçta her bir piksel için yangın tehlike indeksi değeri; ArcGIS 10.5 programında Mekansal Analiz Raster Veri Düzenleme aracı yardımıyla Denklem 1 kullanılarak hesaplanmıştır.

$$
S=\sum_{i=1}^{n}\left(w_{i} x_{i}\right)
$$

S; Toplam yangın tehlike puanı

$\mathrm{w}_{\mathrm{i}}$; Kriterlerin ağırlık değeri

$\mathrm{x}_{\mathrm{i}}$, Kriter puanları

n; Toplam kriter sayısı

Analizlerin sonuçları ve her bir değişken için hesaplanan ağırlık değerleri kullanılarak yangın tehlike indeksi formülü oluşturulmuştur (Denklem 2).

Yangın Risk indeksi $=0.41 \mathrm{C} 1+0.18 \mathrm{C} 2+0.06 \mathrm{C} 3$ $+0.11 \mathrm{C} 4+0.06 \mathrm{C} 5+0.18 \mathrm{C} 6$

Denklem 2'ye göre orman yangını risk haritası oluşturulmuştur (Şekil 7). 


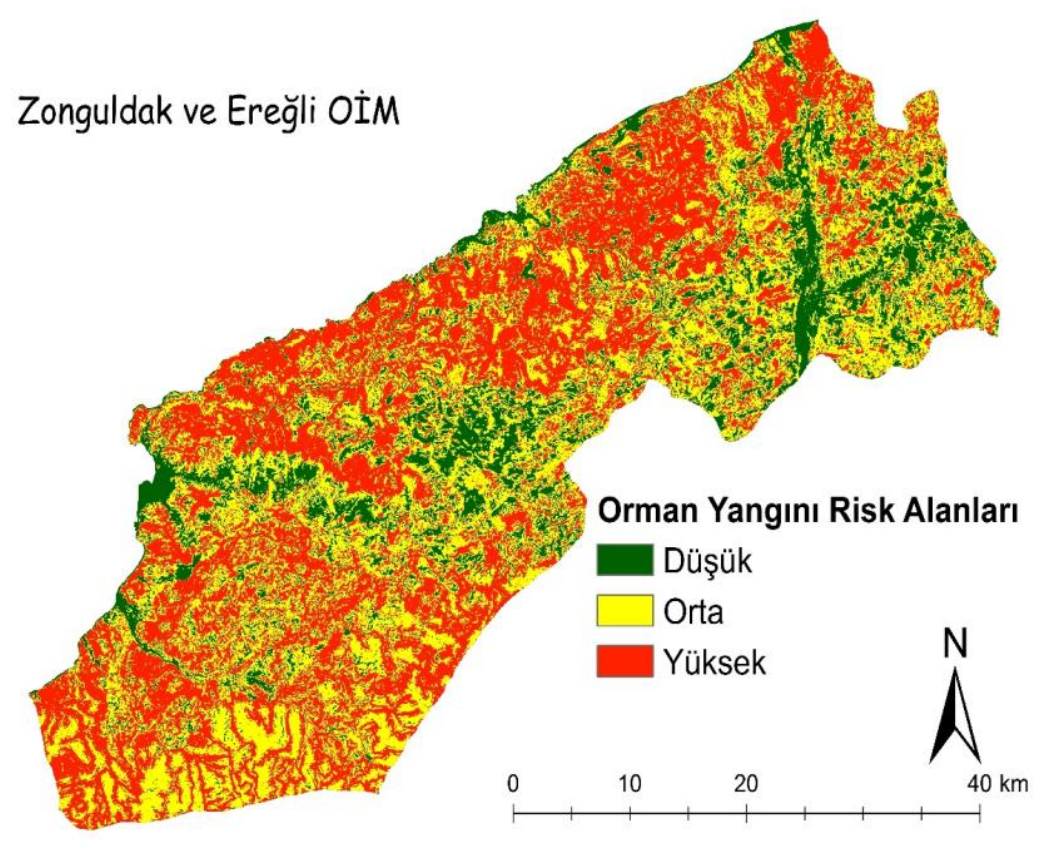

Şekil 7. Zonguldak ve Ereğli Orman Yangını Risk Alanları

Oluşturulan orman yangını risk haritası analiz edilmiştir ve toplam alanın \%18'inin düşük, \%43'ünün orta, \%39'unun ise yangına en hassas olan yüksek risk sınıfında olduğu görülmüştür (Tablo 5).

Tablo 5. Yangın risk sınıflarının tanımlanması ve alansal dağılımı

\begin{tabular}{|c|l|c|}
\hline $\begin{array}{c}\text { Yangın } \\
\text { Tehlike } \\
\text { Sınıfı }\end{array}$ & Yangın risk alanları tanımları & $\begin{array}{c}\text { Alan } \\
\text { (ha) }\end{array}$ \\
\hline Düşük & $\begin{array}{l}\text { Salt tarım, yerleşim, endüstriyel } \\
\text { ve ticari alanlar vd. Karışı ve } \\
\text { yapraklı ormanlık alanlar, düz ve } \\
\text { düze yakın alanlar, sarp ve çok } \\
\text { dik yüksek alanlar }\end{array}$ & $\begin{array}{c}38885.3 \\
(\% 18)\end{array}$ \\
\hline Orta & $\begin{array}{l}\text { Doğal bitki örtüsü ile bulunan } \\
\text { tarım alanları birlikte, orman alt } \\
\text { sınır alanları, orta eğimli ve } \\
\text { kısmen dik eğimli ve orta } \\
\text { yükseklikteki alanlar }\end{array}$ & $\begin{array}{c}91229.8 \\
(\% 43)\end{array}$ \\
\hline \multirow{2}{*}{ Yüksek } & $\begin{array}{l}\text { Doğal bitki örtüsü ile bulunan } \\
\text { tarım alanları, seyrek bitki } \\
\text { alanları, bozuk meşcere alanları, } \\
\text { çok eğimli ve yüksekliği düşük } \\
\text { alanlar }\end{array}$ & $\begin{array}{c}\text { 83119.7 } \\
(\% 39)\end{array}$ \\
\hline \multicolumn{2}{|l|}{ Toplam Alan: 213234.8 ha } \\
\hline
\end{tabular}

Arşiv araştırması sonucu elde edilen 126 adet orman yangınından 25 adedi yangın risk haritasında istatiksel analiz yapmak için ayrılmıștır. Şekil 7'de oluşturulan orman yangını risk haritası üzerinde, 25 adet orman yangınına ait yangın tehlike indeks değerlerine bakılarak bu yangınların hangi risk grubunda çıktığı belirlenmiştir (Tablo 6).

Yangın tehlike indeksi değerleri ile risk grupları arasında SPSS programinda diskriminant analizi yapılmıștır. Bu analiz sonucuna göre çalıșmada elde edilen yangın tehlike indeksi analizi ile değerlerinin, çalışma alanını düşük, orta, yüksek şeklindeki sınıflandırmadaki önemi \%86 olarak çıkmıştır.

Tablo 6. Kontrol için atılan koordinatların yangın tehlike sinıfları

\begin{tabular}{|l|l|l|l|l|}
\hline NN & Y $(\underline{9})$ & $X(\underline{9})$ & $\begin{array}{l}\text { YTİ } \\
\text { değeri }\end{array}$ & $\begin{array}{l}\text { YT } \\
\text { sınıfı }\end{array}$ \\
\hline 1 & 31.676944 & 41.352778 & 4.78 & Orta \\
\hline 2 & 31.859167 & 41.481667 & 5.52 & Yüksek \\
\hline 3 & 31.863056 & 41.454722 & 5.30 & Yüksek \\
\hline 4 & 31.957778 & 41.393611 & 5.00 & Yüksek \\
\hline 5 & 32.012500 & 41.528611 & 4.87 & Orta \\
\hline 6 & 31.928611 & 41.522222 & 4.17 & Orta \\
\hline 7 & 32.088333 & 41.360556 & 4.17 & Orta \\
\hline 8 & 31.915278 & 41.520278 & 5.40 & Yüksek \\
\hline 9 & 32.088333 & 41.367222 & 2.22 & Düşük \\
\hline 10 & 32.012500 & 41.528611 & 4.87 & Orta \\
\hline 11 & 31.735278 & 41.258889 & 4.07 & Orta \\
\hline 12 & 31.481389 & 41.183056 & 4.00 & Orta \\
\hline 13 & 31.595833 & 41.366111 & 5.47 & Yüksek \\
\hline 14 & 31.533611 & 41.237778 & 4.98 & Yüksek \\
\hline 15 & 31.490556 & 41.233056 & 4.01 & Orta \\
\hline 16 & 31.620000 & 41.376667 & 5.29 & Yüksek \\
\hline 17 & 31.641389 & 41.366944 & 5.41 & Yüksek \\
\hline 18 & 31.539167 & 41.242778 & 5.40 & Yüksek \\
\hline 19 & 31.460278 & 41.238889 & 5.76 & Yüksek \\
\hline 20 & 31.641944 & 41.194722 & 4.78 & Orta \\
\hline 21 & 31.931667 & 41.516111 & 4.86 & Orta \\
\hline
\end{tabular}




\begin{tabular}{|l|l|l|l|l|}
\hline 22 & 31.844167 & 41.495833 & 5.22 & Yüksek \\
\hline 23 & 31.906111 & 41.456389 & 4.54 & Orta \\
\hline 24 & 31.520000 & 41.212778 & 4.00 & Orta \\
\hline 25 & 31.850556 & 41.387222 & 5.30 & Yüksek \\
\hline
\end{tabular}

\section{SONUÇLAR ve ÖNERILLER}

Bu çalışmada, Zonguldak ve Ereğli OİM'de bazı doğal ve beşeri faktörlerin orman yangını dağılışına etkisi incelenmiştir. Bunun için Uzaktan Algılama, CBS teknikleri ve AHP yöntemi kullanılmıștır. Çalışma alanı için orman yangın riskini etkileyen faktörler arazi örtü tipi, eğim, bakı, yükseklik, yerleşim ve yol durumu olarak belirlenip analizler bu faktörler üzerinden yapılmıștır. AHP yöntemiyle hesaplanan ağırlıklara göre en baskın faktör arazi örtü tipi olmuştur. Bunu, eğim ve yol hatlarına mesafe takip etmiştir. Üretilen yangın risk haritasına göre toplam alanın \%39'u yangına en hassas olan yüksek risk sınıfında, \%43'ü orta risk sınıfında ve \%18'i düşük risk sınıfında yer almaktadır. Toplam 213234.8 ha alanın 174349.5 ha alanının yangın riski açısından yüksek ve orta kısımda yer aldığı görülmüştür.

Yapılan diskriminant analizi sonucunda; elde edilen yangın risk haritasındaki yangın tehlike indeksi değerlerinin, risk gruplarına ayırmadaki öneminin \%86 olduğu görülmüştür.

Orman yangınları ile müdahale ve yapılacak olan planlamalar için, uydu görüntüleri kullanılarak CBS tabanlı yazilımlar yardımıyla yangın tehlike haritalarının oluşturulması ve belirli aralıklarla tekrarlanması faydalı olacaktır. Çalışmada elde edilen bulgular ve sonuçların; OBM, OİM ve orman işletme şeflikleri de dahil olmak üzere Türkiye genelinde yapilacak planlamalara zemin hazırlayacağı düşünülmektedir. Bunun yanında Zonguldak ve Ereğli OİM'nin sınırları içerisinde olması muhtemel orman yangınlarının önlenmesi için katkıda bulunulacağı öngörülmektedir.

Küresel ısınmanın etkisiyle değişen iklimler orman yangınlarını arttırmaktadır. Yangına hassas alanlardaki tehlike bir kat daha artmakta ve yangına hassas yeni coğrafi bölgelerin oluşmasına neden olmaktadır. İnsan hareketliliği nedeniyle ekolojik dengenin bozulması ve arazi kullanımlarındaki olumsuzluklar bu süreci hızlandırmaktadır. Yapılacak planlamalarda bu alanların tespiti ve önlemlerin alınması gelecek planlamaları için oldukça yararlı olacaktır. Bu nedenle gerçekleştirilen çalışmada kullanılan faktörlere ek olarak iklim, günlük yağıș miktarı, ortalama yıllık hava sıcaklığı, rüzgar hızı vb meteorolojik faktörlerinde dahil edilerek daha farklı yöntem ve modeller geliştirilmesi yangın risk haritalarının doğruluğunu bir üst seviyeye taşıyacak nitelikte olacaktır.

\section{BILGILENDİRME/TEŞEKKÜR}

$\mathrm{Bu}$ çalışma, X.Türkiye Ulusal Fotogrametri ve Uzaktan Algllama Birliği (TUFUAB) Teknik
Sempozyumu - 2019'da sözlü bildiri olarak sunulmuş ve Geomatik Dergisi'nde araştırma makalesi olarak basılması üzere kabul edilmiştir.

Çalışma alanı ile ilgili harita ve diğer verilerin temini, ilgili görüşlerin paylaşımından dolayı Orman Genel Müdürlügüu, Zonguldak OBM, Zonguldak ve Ereğli OİM teknik personel ve çalışanlarına teșekkür ederiz.

\section{KAYNAKÇA}

Adıgüzel, F., Kaya, E., ve Çerçioğlu, M. (2016). Orman Yangınlarının Topografik Özelliklere Bağlı Olarak CBS ve Uzaktan Algılama Verileriyle Analiz Edilmesi: İbecik Orman İşletme Şefliği Örneği. TÜCAUM Uluslararası Coğrafya Sempozyumu, 13-14 Ekim 2016, Ankara, Türkiye.

Ahmad, F., Goparaju, L. (2019). GeospatialAssessment of Forest Fires in Jharkhand (India). Indian Journal of Science and Technology. 10(21):DOI: 10.17485/ijst/2017/v10i21/113215

Ateşoğlu, A. (2014). Forest Fire Hazard Identifying. Mapping Using Satellite Imagery-Geographic Information System and Analytic Hierarchy Process: Bartın, Turkey. In Journal of Environmental Protection and Ecology, 15 (2), 715-725.

Ateşoğlu, A., Melemez, K., ve Uğur B. (2015). Orman Yangınına Hassas Bölgelerde Arazöz ile Müdahale Oranının Belirlenmesi (Bartın Orman İşletmesi Örneği). Artvin Çoruh Üniversitesi Orman Fakültesi Dergisi, 16 (2), 132-143.

Bingöl, B. (2017). Coğrafi Bilgi Sistemleri Kullanarak Burdur İli Orman Yangını Risk Alanlarının Belirlenmesi. Turkish Journal of Forest Science, 1(2), 169-182.

Cömert, R., Matçı, D.K., ve Avdan U. (2019), Object Based Burned Area Mapping With Random Forest Algorithm International Journal of Engineering and Geosciences (IJEG), Vol; 4, Issue; 2, pp. 078-087, June, 2019, ISSN 2548-0960, Turkey

Çepel, N., (1995). Orman Ekolojisi, 4.Baskı, İ.Ü. Basımevi, İstanbul.

Doğanay, H., ve Doğanay, S. (2004). Türkiye'de Orman Yangınları ve Alınması Gereken Önlemler. Doğu Coğrafya Dergisi, 9(11), 31-48.

Dong, X., Li-min, D., Guo-fan, S., Lei, T., and Hui, W. (2005). Forest Fire Risk Zone Mapping From Satellite Images and GIS For Baihe Forestry Bureau, Jilin, China. In Journal of Forestry Research, 16(3), 169-174. 
Erten, E., Kurgun, V., ve Musaoğlu, N. (2005). Uzaktan Algılama ve Coğrafi Bilgi Sistemleri Kullanarak Orman Yangını Bilgi Sisteminin Kurulması. 10.Türkiye Harita Bilimsel ve Teknik Kurultayl, 28 Mart-1 Nisan 2005, Ankara, Türkiye.

Gigovic, L., Jakovljevic, G., Sekulovic, D., and Regodic, M. (2018). GIS Multi-Criteria Analiysis for Identifying and Mapping Forest Fire Hazard: Nevesinje, Bosnia and Herzegovina. Tehnicki Vjesnik, 25(3), 891-897.

Goldammer, J.G., Nikolov, N. (2009). Climate Change and Forest Fires Risk, European and Mediterranean. In: Workshop Climate Change Impact on Water-Related and Marine Risks, October 2009, Murcia, Spain.

Kadak, E.G. (2006). Türkiye'de AHP Tekniğinin Performans Değerlendirmedeki Yeri ve İlaç Dağıtım Sektöründe Uygulanması. Çukurova Üniversitesi Fen Bilimleri Enstitüsü, Endüstri Mühendisliği Anabilim Dalı. Yüksek Lisans Tezi, Adana.

Karakuş, P., Karabörk, H., Kaya, Ş. (2017), A Comparison Of The Classification Accuracies In Determining The Land Cover Of Kadirli Region Of Turkey By Using The Pixel Based And Object Based Classification Algorithms, International Journal of Engineering and Geosciences (IJEG), Vol; 2; , Issue; 02, pp. 52-60, June, 2017, ISSN 2548-0960, Turkey

Küçük, Ö., ve Bilgili, E. (2006). Coğrafi Bilgi Sistemleri Yardımıyla Yangın Davranışının Uygulamaya Aktarılması. Kastamonu Örneği. Gazi Üniversitesi Orman Fakültesi Dergisi, 6(2), 262-273.

Mahdavi, A., Shamsi, S.R.F., ve Nazari, R. (2012).Forest and rangelands' wildfire risk zoning using GIS and AHP techniques. In Caspian Journal of Environmental Sciences, 10(1), 43-52.

Malik, T., Rabbani, G., and Farooq, M. (2013). Forest Fire Risk Zonation Using Remote Sensing and GIS Technology in Kansrao Forest Range of Rajaji National Park, Uttarakhand, İndia. In International Journal of Advanced Remote Sensing and GIS, 2(1), 86-95.

Matin, M. A.et al. (2017). Understanding forest fire patternsand risk in Nepal using remote sensing, geographicinformation system and historical fire data. International Journal of Wildland Fire 26, 276-286.
OGM, (2012) .Ministry of Environment and Foresty General Directore of Foresty. Forest Fire in Turkey. http://www.ogm.gov.tr/ (15.12.2012).

Özşahin, E. (2014). CBS ve AHS kullanılarak Orman Yangını Duyarlılık Analizi: Antakya Orman İşletme Müdürlügü Örneği. In Route Educational and Social Science Journal, 3(1), 50-71.

Öztürk, M., Gücel, S., Küçük, M., ve Sakcalı, S. (2010). Forest Diversity, Climate Change and Forest Fires in the Mediterranean Region of Turkey. Journal of Environmental Biology 31 (1).

Pradhan, B., Suliman, M., and Avang, M. (2007). Forest Fire Susceptibility and Risk Mapping Using Remote Sensing and Geographical İnformation Systems (GIS). Disaster Prevention and Management, 16(3), 344-352.

Saaty, T.L. (1980). The Analytic Hierarchy Process, ISBN 0-07-054371-2, USA.

Yavuz, M, Sağlam, B, Küçük, Ö, Tüfekçioğlu, A. (2018). Assessing forest fire behavior simulation using FlamMap software and remote sensing techniques in Western Black Sea Region, Turkey. Kastamonu University Journal of Forestry Faculty, 18 (2), 171-188. DOI: $10.17475 /$ kastorman.459698

Yavuz, M., ve Sağlam, B., (2011) Uzaktan Algllama ve Coğrafi Bilgi Sistemlerinin Orman Yangınlarında Kullanılması. I.Ulusal Akdeniz Orman ve Çevre Sempozyumu, 26-28 Ekim 2011, Kahramanmaraş, Türkiye.

URL

https://publications.jrc.ec.europa.eu/repositor y/bitstream/JRC108974/jrc108974_final.pdf URL

https://gadm.org/download_country_v3.html

URL 3:

http://www.zonguldak.gov.tr/cografya

URL

https://www.mgm.gov.tr/FILES/iklim/yillikikl im/2018-iklim-raporu.pdf

URL 5:

https://earthexplorer.usgs.gov/

URL 6:

https://gdex.cr.usgs.gov/gdex/ 